\title{
LA HARINA DE CEFALOTÓRAX DE CAMARÓN EN RACIONES PARA GALLINAS PONEDORAS ${ }^{1}$
}

\author{
Catalina Salas-Durán ${ }^{2}$, Alejandro Chacón-Villalobos ${ }^{3}$, Laura Zamora-Sánchez ${ }^{4}$
}

\begin{abstract}
RESUMEN
La harina de cefalotórax de camarón en raciones para gallinas ponedoras. El objetivo de este trabajo fue determinar el efecto de la harina de cefalotórax de camarón (HC) sobre las raciones de gallinas ponedoras comerciales. Entre abril y septiembre de 2013, en Costa Rica, se empleó Pleuroncodes planipes para obtener una harina $(\mathrm{HC})$ con un rendimiento de $15 \%$, tamaño de partícula de $256 \mu \mathrm{g}$ y negativa para Salmonella sp. A la HC se le realizó análisis proximal: proteína cruda $(40,67 \%)$, extracto etéreo $(11,05 \%)$, fibra cruda $(7,12 \%)$, cenizas $(27,48 \%)$, calcio $(9,03 \%)$, fósforo $(2,66 \%)$; perfil de aminoácidos, digestibilidad por pepsina $(84 \%)$ y acidez $(8,34)$. Posteriormente, se realizó un ensayo con 140 gallinas Hy-Line Brown, con 40 semanas de edad, alimentadas durante cuatro semanas con cuatro dietas con niveles crecientes de inclusión de $\mathrm{HC}(0 \%, 5 \%, 10 \%$ y $15 \%$ ), y formuladas según el concepto de proteína ideal y aminoácidos digestibles, manteniéndose isocalóricas e isoprotéicas. Se evaluaron experimentalmente las variables: producción porcentual, consumo de alimento, peso corporal, mortalidad, peso de huevo y conversión alimenticia. Solamente el peso de huevo varió significativamente entre tratamientos en la tercera semana $(\mathrm{p}<0,05)$, presentando las aves suplementadas con $5 \%$ de $\mathrm{HC}$ un mayor peso. Se sugiere evaluar la inclusión de HC hasta en un $15 \%$.
\end{abstract}

\begin{abstract}
Shrimp cephalothorax meal in laying hen diets. The aim of this study was to meassure the effect of shrimp meal (SM) in commercial laying hen diets. From April to September 2013, in Costa Rica, Pleuroncodes planipes was used to obtain a meal (SM) with a yield of $15 \%$, particle size of $256 \mu \mathrm{g}$ and negative for Salmonella sp. Proximate analysis was performed to the SM: crude protein $(40.67 \%)$, ether extract $(11.05 \%)$, crude fiber $(7.12 \%)$, ash $(27.48 \%)$, calcium $(9.03 \%)$, phosphorus $(2.66 \%)$, amino acid profile, pepsin digestibility (84\%) and acidity (8.34). Subsequently, a trial was performed with 140 40-week-old Hy-Line Brown laying hens, fed with four different diets containing increasing levels of inclusion of SM $(0 \%, 5 \%, 10 \%$, and $15 \%$ ) during four weeks; and formulated according to the ideal protein and digestible amino acids concepts; being isocaloric and isoproteic. The variables experimentally evaluated were: production percentage, feed intake, body weight, mortality, egg weight and feed conversion ratio. Only egg weight changed significantly between treatments in the third week $(\mathrm{p}<0.05)$. The hens fed with 5\% SM laid heavier eggs. It is suggested to evaluate a level of SM inclusion up to $15 \%$ in laying hens diets.
\end{abstract}

Keywords: animal feed, animal production, aviculture.

Palabras clave: alimentación animal, producción animal, avicultura.

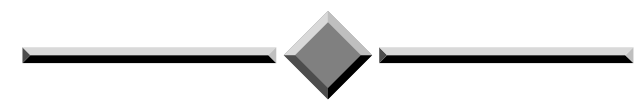

Recibido: 14 de noviembre, 2014. Aceptado: 10 de marzo, 2015. Este trabajo formó parte de la tesis de grado del tercer autor.

2 Universidad de Costa Rica, Facultad de Ciencias Agroalimentarias Escuela de Zootecnia. San José, Costa Rica. catalina.salas@ucr.ac.cr

3 Universidad de Costa Rica, Facultad de Ciencias Agroalimentarias, Estación Experimental Alfredo Volio Mata. Cartago, Costa Rica. alejandro.chacon@ucr.ac.cr

4 Corporación Ganadera (CORFOGA). Ciudad Quesada, San Carlos, Alajuela, Costa Rica. lzamora@corfoga.org 


\section{INTRODUCCIÓN}

La producción mundial de camarón (tanto de captura como de cría) es de alrededor de seis millones de toneladas anuales; y aproximadamente el $60 \%$ de esta cantidad es colocada en el mercado mundial. En términos de valor, el camarón es en la actualidad el producto pesquero más importante comercializado internacionalmente (Gillet, 2010).

En Costa Rica, la industria camaronera es una actividad en desarrollo y crecimiento. De acuerdo con datos del Instituto Costarricense de Pesca y Acuicultura (INCOPESCA, 2013), existen unas 1600 ha dedicadas a la producción de camarón, con una concentración de la actividad en la costa pacífica. Esta actividad involucra alrededor de 118 camaroneros, quienes representan un 7\% del total de acuicultores del país. La mayor parte son pequeños productores del Golfo de Nicoya anteriormente dedicados a la actividad salinera, que a raíz del ingreso de sal procedente de México a bajos precios, se desplazaron a este sector laboral (Blanco, 2008). Entre los años 2008 y 2011, la cantidad de kilogramos totales de exportación de camarón fresco, refrigerado y congelado, aumentó de $298312 \mathrm{~kg}$ a $880044 \mathrm{~kg}$, que en ingresos significó un aumento de $\$ 2171433$ a $\$ 4942055$ (INCOPESCA, 2013).

Los camarones son los crustáceos de mayor interés económico, siendo la cola la parte con utilidad comercial real. La cabeza en contraparte carece de valor económico, representando el cefalotórax entre un 30-48\% del peso total (Pan, 1990; Carmona, 2004). A nivel industrial los subproductos generados durante el procesamiento del camarón se subvaloran, generalmente son vendidos a intermediarios que pagan muy bajos precios, y que colocan esta materia prima en industrias que los destinan a la producción de alimentos para peces o mascotas. El aprovechamiento de este tipo de materiales excedentes de la industria camaronera en la formulación de derivados, da un mayor valor agregado, donde destaca como posibilidad la generación de harinas para consumo animal que son fuente de proteína cruda (30\% a 58\% según Carranco et al. (2011)), y de pigmentos carotenoides (astaxantina) capaces de generar coloraciones consideradas como deseables en la trucha, el salmón, los camarones, y en plumajes de aves exóticas (Gernat, 2001).

La harina de camarón se ha utilizado durante mucho tiempo en Costa Rica, pero ha sido poco estudiada.
La harina de cefalotórax de camarón tiene potencial de aprovechamiento en la alimentación animal, esto como posible sustituto parcial o total de las fuentes convencionales de proteínas (Gernat, 2001), siendo un posible complemento en raciones basadas en granos para mono gástricos. Estas últimas se caracterizan por ser energéticas, las cuales podrían mejorarse al complementarlas con alimentos ricos en minerales, vitaminas, proteína de alta calidad, pigmentos y quitina, como la harina de camarón (Chavarría, 1993). Destacan algunos trabajos realizados, por ejemplo, Chavarría (1993) evaluó la utilización de la harina de exoesqueletos de camarón en la alimentación de gallinas ponedoras y Moreno (1978) estudió el efecto de la sustitución de la harina de pescado por harina de cáscara de camarón en la alimentación de pollos de engorde.

Las dietas de gallinas ponedoras podrían contener harina de cefalotórax de camarón, así lo mostró Gernat (2001) en un estudio en el que utilizó varios niveles de inclusión de la harina $(0 \%, 20 \%, 40 \%, 60 \%$ y $80 \%)$, los cuales no provocan cambios significativos desfavorables en variables como la mortalidad y el peso del huevo, a la vez que si generan para un $40 \%$ y un $80 \%$ de inclusión un aumento significativo del consumo, una mejor conversión alimenticia atribuible, y una pigmentación rojiza más intensa de la yema. Resultados orientados en la misma dirección fueron obtenidos por Carranco et al. (2011), donde inclusiones de harina de camarón $(20 \%)$ y harina de langostilla (4\%) no influyeron negativamente en las variables productivas de las aves (producción y peso del huevo, conversión alimentaria, consumo de alimento por ave), ni modificaron la calidad sensorial del huevo. Se suman a esto los hallazgos de Cruz et al. (1993), donde una suplementación en la dieta del $6 \%$ con dos tipos de harina de camarón de diferente procedencia generó en las aves mejoras en la conversión alimenticia.

El presente trabajo tuvo el objetivo de determinar el efecto de la harina de cefalotórax de camarón (HC) sobre las raciones de gallinas ponedoras comerciales.

\section{MATERIALES Y MÉTODOS}

\section{Localización}

El estudio se efectuó entre abril y septiembre del año 2013 en Costa Rica. La materia fresca de 
camarón para la elaboración de la harina, fue de origen marino y proveniente de proveedores localizados en las provincias costeras de Puntarenas y Guanacaste. La elaboración de la harina se efectuó en la Planta Harinera de la empresa Alimentos Pro Salud S.A., localizada en la comunidad del Roble de la provincia de Puntarenas. Los análisis físicos y químicos de la harina se realizaron en el Centro de Investigación de Nutrición Animal (CINA) de la Universidad de Costa Rica, ubicado en San Pedro de Montes de Oca, San José. El ensayo biológico con gallinas ponedoras tuvo lugar en la Granja Avícola Piedras Negras, localizada en Piedras Negras del cantón de Mora, provincia de San José.

\section{Proceso de obtención de una harina de cefalotórax de camarón}

La materia prima, al provenir de camarones procesados el mismo día de la recolección, presentó un adecuado estado antes de iniciar el proceso. El proceso de selección, recolección y transporte hacia la planta de procesamiento pasó por un procedimiento de supervisión directa para garantizar en todo momento la integridad del material. Este estuvo constituido en esencia por cefalotórax, exoesqueletos y algunos camarones enteros de la especie Pleuroncodes planipes, conocida como "camarón langostino".

La materia prima se trasladó inmediatamente después de la recolección a la planta de producción de harinas, donde inició la técnica de transformación, siguiendo el proceso estándar de esta empresa. A su llegada se procedió al pesaje del material inicial, y a la determinación de humedad (AOAC 930.15), obteniéndose un lote de $1669 \mathrm{~kg}$ totales de materia prima con una humedad inicial de 73,5 $\pm 0,1 \%$.

El material fresco fue depositado en unos tornillos sin fin, los que a medida que mezclan y trocean el material lo transportan hacia un "cocinador continuo", en el cual, el producto fue sometido a una cocción a 90 ${ }^{\circ} \mathrm{C}$ por quince minutos; similar a lo descrito por Andrade et al. (2007) y Chávez et al. (2010). El material cocido pasó a un decantador donde por efecto de la gravedad se separó en tres fases: los sólidos, el agua y los aceites. El agua y los aceites fueron recuperados para su aprovechamiento independiente en la planta, mientras que los sólidos, pasaron a un proceso de prensado. La prensa consistió en un tornillo que iba de menor a mayor tamaño rodeado con una malla que mantiene el mismo tamaño de circunferencia a lo largo de todo el tornillo, lo que generó extracción de humedad. Al salir de la prensa se midió el contenido de humedad del material, resultando ser de 53,3 $\pm 0,1 \%$.

El material escurrido fue pasado a un secador que operó a una temperatura de $110{ }^{\circ} \mathrm{C}$, donde se mantuvo durante una hora. En este tiempo el producto alcanzó una humedad final de $10,0 \pm 0,1 \%$. Finalmente, este se embaló en sacos, recolectándose cinco sacos de $50 \mathrm{~kg}$ cada uno, para un rendimiento aproximado del 15\%. Esto concuerda con los rendimientos obtenidos por Chavarría (1993), quien igualmente obtuvo un $15 \%$.

El equipo que se utilizó en la fabricación de la harina, normalmente se usa para la elaboración de harina de pescado. Por ello, se tomaron precauciones para que no existiera contaminación cruzada, además se permitió, preliminarmente, que alguna cantidad de material de camarón circulara por el equipo antes de iniciar las mediciones formales de este estudio.

El proceso de elaboración de la harina de camarón siguió los estándares ya habituales de la industria Alimentos Pro Salud S.A, sin que se presentara ningún problema técnico de importancia. No obstante, es importante mencionar que dado que el exoesqueleto del camarón es muy liviano, el mismo tendía a adherirse en las paredes de la maquinaria en ciertas etapas del proceso, lo que hacía necesario efectuar ligeros remojos con agua para separar el material. Esto le sumó tiempo al proceso que demoró en total cuatro horas.

\section{Caracterización física y química de la harina de camarón}

Por medio de muestreo aleatorio fueron extraídas sub-muestras de la harina de camarón procesada, con el fin de realizar un análisis proximal de la composición nutricional de la misma. Estas evaluaciones se llevaron a cabo por química húmeda para los parámetros de humedad, extracto etéreo, proteína cruda, fibra cruda, cenizas, calcio y fósforo, según los procedimientos descritos por la AOAC (2010): análisis de humedad a $135^{\circ} \mathrm{C}$ (AOAC 930.15), extracto etéreo (AOAC 920.39), proteína cruda (AOAC 2001.11), cenizas (AOAC 942.05), calcio (AOAC 975.03), fósforo (AOAC 965.17, AOAC 968.24), fibra cruda (AOAC 962.09). Complementariamente se efectuaron evaluaciones de digestibilidad por pepsina (AOAC 
971.09), tamaño de partícula (AOAC 973.03), presencia de Salmonella sp. (AOAC 967.28) y perfil de aminoácidos (Bartolomeo y Maisano, 2006).

Una muestra de $150 \mathrm{~g}$ de la harina de camarón obtenida por sub-muestreo quintuplicado aleatorio, se llevó al laboratorio de química de la Escuela de Tecnología de Alimentos de la Universidad de Costa Rica, para determinar la acidez por medio de un análisis potenciométrico AOAC 981.12 (AOAC, 2010). Pruebas preliminares demostraron que dada la coloración rojiza de la harina de camarón, esta dificultó establecer el punto de viraje de la fenolftaleína al aplicar una valoración convencional con $\mathrm{NaOH} 0,1 \mathrm{~N}$.

\section{Ensayo biológico con gallinas ponedoras}

Una vez que se tuvo la información de los contenidos nutricionales de la harina de camarón elaborada, se procedió a realizar un estudio de alimentación de gallinas ponedoras. Para el ensayo se utilizaron 140 gallinas de la línea Hy-Line variedad Brown, con una edad de cuarenta semanas.

Los tratamientos consistieron en tres niveles de inclusión de la harina de camarón en la dieta, a razón de $5 \%, 10 \%$ y $15 \%$, y una dieta control (sin camarón). Las dietas fueron formuladas de acuerdo con los requerimientos nutricionales de las aves según la línea genética, realizando la formulación con proteína ideal y aminoácidos digestibles para un consumo de $105 \mathrm{~g} /$ ave, además se mantuvieron isocalóricas e isoproteicas (18\% proteína cruda y $2850 \mathrm{kcal}$ ). En las dietas que se incluyó harina de camarón fue necesario adicionar fosfato monocálcico como ingrediente. Esto debido a que el sistema de formulación disminuyó la inclusión de harina de carne y hueso, la cual fue sustituida como fuente de proteína por la harina de camarón, sin embargo, la misma contenía menor cantidad de fósforo en su composición, por lo que surgió la necesidad de incluir el fosfato en las dietas experimentales (Cuadro 1).

El periodo experimental fue de cuatro semanas, durante las cuales las variables estudiadas fueron: producción porcentual, consumo de alimento, peso corporal, mortalidad, peso de huevo y conversión alimenticia.

Las aves estuvieron dispuestas en baterías de jaulas de tres niveles y se manejaron siete animales por jaula empleando un criterio de densidad animal adecuado (UNAM, 2014). En total se utilizaron veinte jaulas (unidades experimentales), cada tratamiento
Cuadro 1. Formulaciones de las raciones experimentales usadas para alimentar las gallinas ponedoras comerciales línea Hy-Line variedad Brown. San José, Costa Rica. 2014.

Table 1. Formulations of the experimental diets used to feed commercial Hy-Line Brown laying hens. San José, Costa Rica. 2014.

\begin{tabular}{|c|c|c|c|c|}
\hline $\begin{array}{l}\text { Ingredientes } \\
(\%)\end{array}$ & Control & $5 \% \mathrm{HC}$ & $10 \% \mathrm{HC}$ & $15 \% \mathrm{HC}$ \\
\hline Maíz & 58,10 & 55,02 & 56,84 & 57,68 \\
\hline Soya $47 \%$ & 20,11 & 23,19 & 17,45 & 13,34 \\
\hline $\begin{array}{l}\text { Carbonato de } \\
\text { calcio }\end{array}$ & 8,76 & 8,93 & 7,88 & 7,05 \\
\hline $\begin{array}{l}\text { Harina de } \\
\text { camarón }\end{array}$ & - & 5,00 & 10,00 & 15,00 \\
\hline Harina de carne & 5,98 & 0,08 & 0,76 & 0,15 \\
\hline Acemite de trigo & 3,91 & 3,74 & 4,00 & 4,00 \\
\hline Aceite de soya & 1,96 & 2,05 & 1,30 & 1,00 \\
\hline $\begin{array}{l}\text { Fosfato } \\
\text { Monocálcico }\end{array}$ & - & 0,86 & 0,53 & 0,43 \\
\hline Sal & 0,40 & 0,40 & 0,40 & 0,40 \\
\hline $\begin{array}{l}\text { Secuestrante de } \\
\text { micotoxinas }\end{array}$ & 0,27 & 0,27 & 0,27 & 0,27 \\
\hline Metionina & 0,23 & 0,23 & 0,24 & 0,27 \\
\hline Lisina & 0,11 & 0,07 & 0,13 & 0,18 \\
\hline $\begin{array}{l}\text { Pre mezcla de } \\
\text { vitaminas y } \\
\text { minerales }\end{array}$ & 0,10 & 0,10 & 0,10 & 0,10 \\
\hline Colina $60 \%$ & 0,05 & 0,05 & 0,05 & 0,05 \\
\hline Treonina & 0,02 & 0,01 & 0,05 & 0,08 \\
\hline Lucantin rojo & 0,002 & - & - & - \\
\hline Total & 100,00 & 100,00 & 100,00 & 100,00 \\
\hline
\end{tabular}

HC= Harina de camarón / Shrimp meal.

(inclusiones de $0 \%, 5 \%, 10 \%$ y $15 \%$ ) contó con cinco repeticiones asignadas completamente al azar. Para la variable de peso corporal de la gallina, se seleccionó una jaula por tratamiento de manera completamente aleatoria, para cuatro jaulas, una por cada tratamiento. Las aves de cada una de estas jaulas fueron las que se continuaron pesando a lo largo del periodo experimental. El análisis de varianza (ANOVA) de los resultados obtenidos en el ensayo se realizó por 
medio de un diseño completamente al azar, utilizando un nivel de confianza del $95 \%$. Se aplicó la prueba de Tukey con el fin de determinar el grado de diferencia entre los tratamientos.

\section{RESULTADOS Y DISCUSIÓN}

\section{Caracterización física y química de la harina de camarón}

Humedad. Los valores de humedad para la harina de camarón evaluada se encontraron dentro del rango reportado en la literatura (Cuadro 2), el cual va de un $3,3 \%$ a $14,1 \%$ para harinas provenientes de subproductos de desechos de camarón de diferente origen (Fanimo et al., 2000; Carranco et al., 2011; Mata, 2011). Conocer el contenido de humedad de un ingrediente es importante, ya que cambios en el peso del alimento debidos a la variación en el contenido de humedad, alteran las concentraciones de nutrientes que se suplementan al animal (Nennich y Chase, 2007).

Cuadro 2. Contenido nutricional, tamaño de partícula y presencia de Salmonella sp para la harina de cefalotórax de camarón empleada en raciones para gallinas ponedoras comerciales línea Hy-Line Brown. San José, Costa Rica. 2014.

Table 2. Nutrient content, particle size, and presence of Salmonella sp in cephalothorax shrimp meal used in portions for commercial Hy-Line Brown laying hens. San José, Costa Rica. 2014.

\begin{tabular}{lc}
\hline Parámetro & Química húmeda \\
\hline Humedad (\%) & $11,30 \pm 0,04$ \\
Humedad a $135^{\circ} \mathrm{C}(\%)$ & $12,85 \pm 0,04$ \\
Extracto etéreo (\%) & $11,05 \pm 0,33$ \\
Proteína (\%) & $40,67 \pm 0,66$ \\
Cenizas (\%) & $27,48 \pm 0,62$ \\
Calcio (\%) & $9,03 \pm 0,54$ \\
Fósforo (\%) & $2,66 \pm 0,22$ \\
Fibra Cruda (\%) & $7,12 \pm 0,07$ \\
Digestibilidad por pepsina (\%) & $84,32 \pm 1,64$ \\
pH & $8,34 \pm 0,08$ \\
Tamaño de partículas $(\mu \mathrm{m})$ & $256,31 \pm 1,27$ \\
Salmonella sp & Ausente en 25 g \\
\hline
\end{tabular}

Proteína cruda. El nutriente encontrado en mayor proporción fue la proteína, la cual representó el 40,67\% del material (Cuadro 2). Lo anterior puede atribuirse al hecho de que, a diferencia de los animales de granja terrestres, los camarones son capaces de obtener más energía metabolizable del catabolismo de las proteínas que de los carbohidratos (FAO, 1989). El contenido de proteína obtenido fue mayor al 33,75\% reportado por Carranco et al. (2011) para una harina elaborada a partir de camarón $P$. planipes, así como también lo fue para el 35\% reportado por Chavarría (1993) para una harina en base a una mezcla de cabezas de camarón de diferentes especies, y para el $39,4 \%$ expuesto por Fanimo et al. (2000). En contraste, el valor obtenido fue menor al rango de $44,1 \%$ a $64,8 \%$ que reportó Mata (2011) para harinas provenientes de diferentes especies. Otros autores han reportado rangos mucho más amplios que van desde 21,2 a 54,7\% (Civera et al., 1996). Esto puede deberse a la composición de la materia prima para la elaboración de la harina, ya que una mayor proporción de cabezas y camarones enteros generarían como resultado valores más altos de proteína, mientras que una mayor proporción de exoesqueletos o conchas disminuirían ese valor.

Fanimo et al. (2000) encontraron que la proteína de la harina de camarón fue en apariencia de menor calidad respecto a una harina de pescado. Sin embargo, al utilizar aminoácidos sintéticos (metionina y lisina), obtuvieron resultados similares para proporción de eficiencia de la proteína, retención neta y utilización neta de la proteína, además de otros indicadores sanguíneos en ratas.

Este subproducto de las plantas procesadoras de camarón tiene el potencial de ser una fuente de proteína alternativa en raciones de animales, sustituyendo parcial o totalmente las fuentes convencionales, tales como harina de soya, harinas de carne y hueso, y la harina de pescado, que en la mayoría de los casos son importadas o poco accesibles (Gernat, 2001).

Aminoácidos. En general, el perfil de aminoácidos obtenido para esta harina (Cuadro 3) fue menor a los reportes en la literatura (Gernat, 2001; Fanimo et al., 2006), sin embargo, esos estudios fueron realizados en Panamá y en Nigeria, donde las especies utilizadas son mayoritariamente de la familia Penaeidae, por lo que no puede descartarse que exista una diferencia comparativa con el contenido de aminoácidos existente en la especie $P$. planipes utilizada en el presente estudio. 
Cuadro 3. Perfil porcentual de aminoácidos totales en la harina de cefalotórax de camarón empleada en raciones para gallinas ponedoras comerciales línea Hy-Line Brown. San José, Costa Rica. 2014.

Table 3. Percentage content of total amino acids in shrimp cephalothorax meal used in portions for commercial Hy-Line Brown laying hens. San José, Costa Rica. 2014.

\begin{tabular}{|c|c|c|c|}
\hline Esenciales & $\begin{array}{c}\text { Porcentaje } \\
(\%)\end{array}$ & $\begin{array}{c}\text { No } \\
\text { esenciales }\end{array}$ & $\begin{array}{c}\text { Porcentaje } \\
(\%)\end{array}$ \\
\hline Metionina & $0,592 \pm 0,030$ & $\begin{array}{c}\text { Ácido } \\
\text { aspártico }\end{array}$ & $0,986 \pm 0,049$ \\
\hline Lisina & $0,259 \pm 0,013$ & Serina & $0,473 \pm 0,024$ \\
\hline Arginina & $3,120 \pm 0,156$ & $\begin{array}{c}\text { Ácido } \\
\text { glutámico }\end{array}$ & $1,393 \pm 0,070$ \\
\hline Triptófano & $0,162 \pm 0,008$ & Glicina & $1,030 \pm 0,052$ \\
\hline Isoleucina & $1,174 \pm 0,059$ & Alanina & $1,517 \pm 0,076$ \\
\hline Leucina & $4,551 \pm 0,228$ & Cisteína & $0,113 \pm 0,006$ \\
\hline Fenilalanina & $4,751 \pm 0,238$ & & \\
\hline Histidina & $0,604 \pm 0,030$ & & \\
\hline
\end{tabular}

La harina generada en el presente estudio presentó valores comparativamente altos en cuanto a contenido de fenilalanina, leucina, arginina, alanina, ácido glutámico, isoleucina, y glicina. Sriket et al. (2007) evaluaron la composición nutricional de dos especies de camarón de la familia Penaeidae y encontraron que en ambas especies los aminoácidos presentes en mayor abundancia fueron arginina, prolina, leucina, isoleucina, fenilalanina y ácido glutámico. Por otro lado, Heu et al. (2003) también encontraron altos niveles de fenilalanina y ácido glutámico en harina de subproductos de camarón Pandalus borealis y Trachypena curvirostris. Otros reportes también indican contenidos mayores de algunos aminoácidos esenciales como arginina, histidina, isoleucina, leucina, fenilalanina y treonina (Ezquerra et al., 1997). Lo anterior podría sugerir indicios de contenidos altos de algunos aminoácidos esenciales en los camarones independientemente de la especie estudiada.

Algunos autores indican que la harina de camarón es particularmente rica en lisina (Fanimo et al., 1996; Heu et al., 2003); sin embargo, los niveles obtenidos para la harina sujeta a estudio en este trabajo estuvieron muy por debajo de esos niveles reportados.

Cenizas, calcio y fósforo. Las cenizas fueron la segunda fracción más alta en términos de contenido nutricional (Cuadro 2), hecho atribuible al alto contenido de minerales del camarón, especialmente de calcio y fósforo derivados de un exoesqueleto que en los crustáceos suele estar calcificado (FAO, 1989; Barrientos, 2003).

La literatura indica contenidos de ceniza que van desde 12,8 - 35,9\% (Civera et al., 1996, Fanimo et al., 2000). En este caso, el contenido de cenizas fue un poco mayor $(25,9 \%)$ en comparación con el $20,24 \pm 0,03 \%$ reportado por Carranco et al. (2011) para una harina de camarón de la misma especie. Esto posiblemente se debió a una mayor cantidad de exoesqueletos presentes porcentualmente en la materia prima utilizada.

El contenido de calcio fue ligeramente menor $(8,46 \%)$ a lo reportado por los autores mencionados anteriormente $(9,97 \pm 0,05 \%)$. Sin embargo, los resultados obtenidos están dentro de los ámbitos reportados por Mata (2011), tanto para calcio $(5,2 \%$ a $11,5 \%)$, como para fósforo (1,3\% a $2,7 \%)$, esto en harinas de camarón procedentes de distintas especies.

Extracto etéreo. El resultado de extracto etéreo fue mayor $(11,05 \%)$ al reportado por Carranco et al. (2011) de 7,29 \pm 0,01\% para una harina de camarón de la misma especie utilizada en este estudio. Otras fuentes indican concentraciones de grasa variables en un intervalo de 2,68\% a 21\% (Civera et al., 1996; Fanimo et al., 2000). Los resultados obtenidos fueron congruentes con los reportados por Mata (2011), quien señala valores promedio de $11,5 \%$ para extracto etéreo.

Fibra cruda. El contenido de fibra cruda encontrado para esta harina fue menor $(7,50 \%)$ a lo señalado en la literatura. Contenidos de $11,38 \%$ de fibra cruda para una harina de camarón de especie no definida fueron obtenidos por Gernat (2001), $12,3 \%$ por Fanimo et al. (2000) y un rango que va de 10,3 a $24,7 \%$ por Mata (2011). Este bajo contenido de fibra contribuye a mejorar la digestibilidad de la harina de camarón, lo que se ve reflejado en una alta digestibilidad por pepsina (Cuadro 2).

Tamaño de partícula. El resultado obtenido para el de tamaño de partícula coincide con una granulometría adecuada para la utilización de la harina en la alimentación de varias especies animales (Cuadro 2). En gallinas ponedoras, por ejemplo, lo ideal es que como máximo en el alimento concentrado se incluya $15 \%$ de partículas menores a $0,5 \mathrm{~mm}$ (ISA-Hendrix Genetics Company, 2009). En cerdos, la reducción de tamaño de partícula en la harina de 
camarón no afectó la utilización de nitrógeno o la biodisponibilidad de la lisina, sin embargo, la partícula fina $(0,5 \mathrm{~mm})$ disminuyó la digestibilidad aparente de la fibra detergente ácida y quitina, y tendió a disminuir las digestibilidades de la materia seca, nitrógeno, cenizas y fibra detergente neutro (Fanimo et al., 2006). En general, existe un aumento en el interés por los efectos del tamaño de partícula en años recientes, ya que los actores de la industria buscan maneras de optimizar la utilización del alimento y mejorar la eficiencia de la producción (Amerah et al., 2007). El efecto del tamaño de partícula debe ser evaluado para cada especie y para cada etapa productiva, lo cual se sale del alcance de este estudio.

Acidez. Con respecto al análisis de acidez, se encontró que la harina fue alcalina presentando un $\mathrm{pH}$ de 8,34. Esto es muy conveniente desde el punto de vista del almacenamiento de la harina, ya que según Torres (2012), una materia prima de origen animal de alto $\mathrm{pH}$ presenta un bajo nivel de descomposición, siempre y cuando se controlen factores ambientales como humedad y temperatura. Además un $\mathrm{pH}$ alto podría constituir una barrera contra bacterias y otros microorganismos asociados al deterioro, pues la mayoría de los microorganismos crecen mejor a valores de $\mathrm{pH}$ en torno a 7,0 $(6,6-7,5)$ (Andino y Castillo, 2010).

Salmonella. El análisis realizado a la harina de camarón para el presente ensayo arrojó resultados negativos para la presencia de Salmonella sp. Lo anterior indica que la materia prima utilizada tuvo un manejo adecuado, obteniéndose un producto sin contaminación. La salmonelosis en humanos es usualmente atribuida al consumo de alimentos contaminados, como productos avícolas, cerdo, res, huevos y productos frescos. Adicionalmente, un incremento en el consumo per cápita de cerdo y productos avícolas también vienen a contribuir con un incremento potencial de exposición a Salmonella (Foley et al., 2008). En el caso de las aves, las mismas se pueden ver infectadas de manera vertical (de las reproductoras a los huevos) o de manera horizontal ya sea a través de la incubadora, de infecciones, del equipo de transporte, el alimento, etc. (Lahellec y Colin, 1985; Opitz et al., 1993). A pesar de que trazar la contaminación a su fuente principal es difícil, algunas epidemias grandes han podido ser relacionadas con alimento contaminado (Crump et al., 2002). Es por esto que se han tomado una serie de medidas para disminuir el impacto que tiene la Salmonella en las explotaciones pecuarias, entre ellas, garantizar la inocuidad de los alimentos animales.

Es importante destacar que el camarón varía mucho en su composición química, ya que depende de las distintas condiciones de captura, zona de producción, clima, especie y época del año (Chavarría, 1993). Es debido a esto que resulta difícil establecer comparaciones entre harinas de diversa procedencia, por lo que es importante caracterizar la harina de manera periódica.

Todo nuevo ingrediente que se utilice en la alimentación de animales con fines productivos va a tener un efecto tanto en el animal como en el producto final. En este caso particular, la harina de camarón aportó nutrientes importantes como proteína, minerales (Ca, Mg, Na y K) y quitina (Carranco, 2002), debido a la gran cantidad de carbonato de calcio presente en el cefalotórax. También es rica en vitamina A y en hierro (Chavarría, 1993).

\section{Ensayo biológico con gallinas ponedoras}

Para todas las variables, el valor $p$ se calculó para detectar diferencias entre tratamientos en cada semana, y para detectar diferencias significativas entre semanas en cada tratamiento.

Las variables porcentaje de postura, consumo de alimento, índice de conversión alimenticia, peso corporal y mortalidad, no presentaron diferencias significativas durante el periodo de ensayo (Cuadro 4), lo cual fue congruente con los hallazgos de Cedeño (2013). Resultados similares se reportan en la literatura; Gernat (2001) reportó que al sustituir harina de soya por harina de camarón en los niveles de $0 \%$, $20 \%, 40 \%, 60 \%$ y $80 \%$ no hubo efecto en porcentaje de producción. De igual manera Carranco (2002) no encontró diferencias significativas en la medición de variables productivas al sustituir con harina de camarón (Panaeus sp.) en los niveles de 0\%, 10\%, $20 \%$ y $25 \%$ a la harina de soya. También Carranco et al. (2011) reportaron porcentajes de postura y consumo de alimento similares a los obtenidos en este estudio, al reemplazar la harina de soya por harina de camarón (Litopenaeus spp.) en un 20\% y en otro tratamiento harina de langostilla en un $4 \%$ (Pleuroncodes planipes) en las raciones de gallinas ponedoras comerciales. 
La ausencia de diferencias significativas en peso corporal se pudo deber a que el consumo de alimento concentrado en ninguno de los tratamientos se vio afectado, lo que contribuyó a que las aves mantuviesen su peso corporal a lo largo del ensayo biológico. El aporte nutricional de la harina de camarón en los niveles de inclusión estudiados fue bien aprovechado por las aves, dando pie a indicios de que no existió ninguna interferencia con la digestibilidad del material que pudiese ser atribuible a algún factor anti nutricional, y más importante aún, a que las dietas en base a harina de camarón no se desempeñaron mal comparándolas con las dietas convencionales, representando entonces una alternativa viable.

Los promedios semanales para los diferentes tratamientos presentaron un comportamiento normal para conversión alimenticia, incluso con índices mejores a los 2,02 kg alimento/kg huevos sugerido por la Guía de Manejo Comercial para la línea genética Hy-Line variedad Brown (2009-2011). Resultados similares encontraron Carranco (2002) y Carranco et al. (2011), al analizar el efecto de la inclusión de harinas de crustáceos en la alimentación de gallinas ponedoras comerciales.

El peso de los huevos no varió entre los tratamientos, excepto en la tercera semana del ensayo, donde se dio un mayor peso promedio $(\mathrm{p}<0,05)$ para los huevos producidos por las gallinas alimentadas con la ración que incluía 5\% de harina de camarón (Cuadro 4). Es difícil atribuir este aumento de peso en huevo a la presencia de harina de camarón en la alimentación de las aves para las condiciones experimentales del presente estudio (Gernat, 2001; Carranco, 2002; Carranco et al., 2011).

A pesar de que solamente en la semana 3 se presentaron diferencias significativas para peso de huevo, en las demás semanas se observó una tendencia a un mayor peso promedio para el tratamiento en donde se incluyó 5\% de harina de camarón en las dietas. Esto permitiría especular una optimización del peso del huevo con niveles de inclusión de 5\% de harina de camarón, basado en una posible relación cuadrática entre el nivel de inclusión de harina de camarón en la dieta y peso de huevo. Esta tendencia debe evaluarse en algún estudio posterior durante un periodo más largo en la vida del ave y para un mayor número de repeticiones. La posibilidad de comprobar la existencia de este efecto es interesante desde un punto de vista económico, ya que un mayor
Cuadro 4. Rendimiento zootécnico de gallinas ponedoras comerciales línea Hy-Line variedad Brown de 40 semanas de edad, alimentadas con harina de camarón. San José, Costa Rica. 2014.

Table 4. Performance of 40 -week- old commercial HyLine Brown laying hens fed with shrimp meal. San José, Costa Rica. 2014.

\begin{tabular}{|c|c|c|c|c|}
\hline \multirow{2}{*}{$\begin{array}{l}\text { Variable/ } \\
\text { Tratamiento }\end{array}$} & \multicolumn{4}{|c|}{ Período de evaluación } \\
\hline & Semana 1 & Semana 2 & Semana 3 & Semana 4 \\
\hline \multicolumn{5}{|c|}{ Porcentaje postura $(\%)$} \\
\hline Control & 91,90 & 91,84 & 88,98 & 90,44 \\
\hline $5 \% \mathrm{HC}$ & 88,58 & 87,36 & 89,00 & 87,36 \\
\hline $10 \% \mathrm{HC}$ & 87,76 & 86,94 & 91,02 & 85,70 \\
\hline $15 \% \mathrm{HC}$ & 88,58 & 90,20 & 92,26 & 93,06 \\
\hline \multicolumn{5}{|c|}{ Consumo (g/ave/día) } \\
\hline Control & 97,03 & 94,59 & 102,98 & 103,21 \\
\hline $5 \% \mathrm{HC}$ & 97,96 & 102,04 & 97,96 & 97,96 \\
\hline $10 \% \mathrm{HC}$ & 97,96 & 102,04 & 97,96 & 97,96 \\
\hline $15 \% \mathrm{HC}$ & 97,96 & 102,04 & 97,96 & 97,96 \\
\hline \multicolumn{5}{|c|}{ Conversión alimenticia } \\
\hline Control & 1,72 & 1,69 & 1,89 & 1,85 \\
\hline $5 \% \mathrm{HC}$ & 1,79 & 1,89 & 1,75 & 1,77 \\
\hline $10 \% \mathrm{HC}$ & 1,86 & 1,94 & 1,75 & 1,83 \\
\hline $15 \% \mathrm{HC}$ & 1,82 & 1,91 & 1,75 & 1,69 \\
\hline \multicolumn{5}{|c|}{ Peso de huevo (g) } \\
\hline Control & 61,7 & 61,0 & $61,6 \mathrm{~b}$ & 62,5 \\
\hline $5 \% \mathrm{HC}$ & 62,3 & 62,2 & $63,3 \mathrm{a}$ & 63,3 \\
\hline $10 \% \mathrm{HC}$ & 60,3 & 61,2 & $61,6 \mathrm{ab}$ & 62,6 \\
\hline $15 \% \mathrm{HC}$ & 61,2 & 61,6 & $60,9 \mathrm{~b}$ & 62,4 \\
\hline \multicolumn{5}{|c|}{ Peso corporal (kg) } \\
\hline Control & 1,86 & 1,91 & 1,86 & 1,75 \\
\hline $5 \% \mathrm{HC}$ & 1,87 & 1,86 & 1,87 & 1,83 \\
\hline $10 \% \mathrm{HC}$ & 1,82 & 1,83 & 1,80 & 1,79 \\
\hline $15 \% \mathrm{HC}$ & 1,83 & 1,79 & 1,79 & 1,75 \\
\hline
\end{tabular}

En la misma columna, medias con diferentes letras son significativamente diferentes $(\mathrm{p} \leq 0,05) /$ In the same column, means with different letters are significantly different $(\mathrm{p} \leq 0.05)$.

peso de huevo sería beneficioso para el productor que decidiera utilizar esta materia prima, debido a que en Costa Rica el huevo se comercializa por kilogramo. 
Gernat (2001), al emplear diferentes grados de inclusión de harina de camarón a los evaluados en el presente estudio ( $40 \%$ y $80 \%$ en las dietas), no encontró diferencias significativas entre tratamientos para las variables de mortalidad y peso del huevo; mientras que para el consumo de alimento se dio un aumento significativo, afectando también la conversión alimenticia. El autor justifica este aumento por el contenido de quitina de la harina.

En México, se evaluó el efecto de la inclusión de la harina de cabezas de camarón en diferentes niveles $(0 \%$, $10 \%, 20 \%$ y $25 \%$ ) remplazando la harina de soya en las raciones de gallinas ponedoras (Carranco, 2002). La inclusión de la harina no afectó las variables productivas de los animales, exceptuando que hubo una disminución en el consumo de alimento con un nivel de inclusión de 25\%; lo que posiblemente se debió a la cantidad de sal que se encuentra en la harina. Esto no fue significativo, reflejándose en los resultados de índice de conversión y el porcentaje de postura. El peso del huevo tampoco se vio significativamente afectado $(\mathrm{p}>0,05)$.

En otro estudio se evaluó el efecto de harinas de crustáceos sobre variables productivas de gallinas ponedoras y sensoriales del huevo. La investigación demostró que la incorporación de harina de camarón $(20 \%)$ y harina de langostilla (4\%) no tuvo efectos negativos en las variables productivas de las aves (producción de huevo, peso del huevo, conversión alimentaria, consumo de alimento por ave) (Carranco et al., 2011).

Con los resultados obtenidos en el presente estudio, se podría sugerir la inclusión de harina de camarón hasta un nivel de $15 \%$ en la dieta de gallinas ponedoras, sin afectar los rendimientos zootécnicos de las aves. El aporte de las harinas de cabeza de camarón a la alimentación animal es de gran utilidad, ya que la mayor proporción de la ración suministrada a aves está compuesta por granos, los cuales no suministran los aminoácidos esenciales en las cantidades adecuadas, siendo principalmente fuentes energéticas, por lo tanto, se hace necesario complementar estas dietas con alimentos ricos en minerales, vitaminas, así como proteína de alta calidad y otros componentes como pigmentos y quitina (Chavarría, 1993).

En el área de avicultura, los estudios realizados han sido enfocados principalmente al efecto pigmentante de la harina de camarón en la yema de huevo. Esto debido a que el contenido de carotenoides de la misma es elevado 10-16 mg/100 g (Civera et al., 1996). Sin embargo, existen pocos reportes del efecto de este material sobre la condición física y estado productivo del animal, así como sobre otras características de la calidad del huevo, por lo que el presente estudio vino a complementar esa información.

\section{AGRADECIMIENTOS}

Los autores desean expresar su agradecimiento a: Alimentos Pro Salud S.A. por la manufactura de la harina de camarón, al Sr. Mario Naranjo, dueño de la Granja Avícola Piedras Negras donde se realizó el ensayo, al Centro de Investigaciones en Nutrición Animal y a la Escuela de Tecnología de Alimentos de la Universidad de Costa Rica por la realización de los análisis de las muestras de harina.

\section{LITERATURA CITADA}

Amerah, A.M., V. Ravindran, R.G. Lentle, and D.G. Thomas. 2007. Influence of feed particle size and feed form on the performance, energy utilization, digestive tract development, and digesta parameters of broiler starters. Poult. Sci. 86:2615-2623.

Andino F., e Y. Castillo. 2010. Curso microbiología de alimentos: un enfoque práctico para la inocuidad alimentaria. Wordpress. https://avdiaz.files.wordpress. com/2010/02/documento-microbiologia.pdf (consultado 22 oct. 2014).

Andrade, R.D., M.M. Chávez, y V. Naar. 2007. Evaluación de las etapas de cocción y secado en la obtención de harina de cabezas de camarón de cultivo (Penaeus sp.). Dyna Rev. Fac. Nac. Minas. 74:181-186.

AOAC (Association of Official Analytical Chemists). 2010. Official methods of analysis of AOAC International. $17^{\circ} \mathrm{ed}$. AOAC International. Gaithersburg, MD, USA.

Barrientos, Z. 2003. Zoología general. Editorial Universidad Estatal a Distancia, CRC.

Bartolomeo, M.P., and F. Maisano. 2006. Validation of a reversed-phase HPLC method for quantitative amino acid analysis. J. Biomol Tech. 17:131-137.

Blanco, P. 2008. Costa Rica con alto potencial para cultivo de camarón orgánico. INCODESO. http://www. incodeso.org/archivos/Crisol_213_Camaron\%20 organico_22-05-08.pdf (consultado 22 oct. 2014). 
Carmona, L. 2004. Evaluación técnica del proceso de extracción y cuantificación de diferentes compuestos (pigmentos carotenoides, proteínas, quitina/quitosano, D-glucosamina) a partir del cefalotórax de camarón. Tesis Lic., Universidad de Costa Rica, San José, CRC.

Carranco, M.E. 2002. Inclusión de harina de cabezas de camarón (Panaeus sp.) en raciones para gallinas ponedoras y su efecto sobre la concentración de pigmento rojo de yema y calidad del huevo. Tesis M.Sc., Universidad de Colima, Colima, MEX.

Carranco, M.E., C.C. Calvo, D.S. Carrillo, C.R. Ramírez, B.E. Morales, G.L. Sanginés, M.B. Fuente, G.E. Ávila, y R.F. Pérez. 2011. Harina de crustáceos en raciones de gallinas ponedoras: efecto en las variables productivas y evaluación sensorial de huevos almacenados en diferentes condiciones. Cuban J. Agr. Sci. 45:171-175.

Cedeño, E.A. 2013. Evaluación de la inclusión de cuatro niveles de harina de cabezas de camarón en dietas para pollos de engorde. Tesis Lic., Universidad Técnica De Manabí, Manabí, ECU.

Chavarría, A. 1993. Efecto de la harina de cefalotórax de camarón sobre la pigmentación en la yema de huevo y contenido de colesterol en carne de pollo y huevos. Tesis Lic., Universidad de Costa Rica, San José, CRC.

Chávez, D. R., M.G. López, y F. Cornejo. 2010. Factibilidad técnica para el aprovechamiento integral del camarón de la especie Penaeus vannamei. Escuela Superior Politécnica del Litoral. http://www. dspace.espol.edu.ec/bitstream/123456789/8840/1/ Factibilidad $\% 20 t \%$ C $3 \%$ A 9 cnica $\% 20$ para $\% 20$ el\%20 aprovechamiento\%20integral\%20del\%20 Camar\%C3\%B3n.pdf (consultado 22 oct. 2014).

Civera, R., H. Villareal, E. Goytortúa, S. Rocha, F. Vega, H. Nolasco, J. Pastén, y T. Camarillo. 1996. Uso de la langostilla (Pleuroncodes planipes) como fuente de proteína en dietas experimentales para camarón. En: L.E. Cruz et al., editores, Avances en Nutrición Acuícola III. Memorias del Tercer Simposio Internacional de Nutrición y Tecnología de Alimentos. Universidad Autónoma de Nuevo León. Monterrey, MEX. p. 325-348.

Crump, J.A., P.M. Griffin, and F.J. Angulo. 2002. Bacterial contamination of animal feed and its relationship to human foodborne illness. Clin. Infect. Dis. 35:859865.

Cruz, L.E., D. Ricque, J.A. Martínez, and P. Wesche. 1993. Evaluation of two shrimp by-product meals as protein sources in diets for Penaeus vannamei. Aquaculture. 115:53-62.

Ezquerra, J.M., F.L. García, R. Civera, and N.F. Haard. 1997. $\mathrm{pH}$-stat method to predict protein digestibility in white shrimp (Penaeus vannamei). Aquaculture 157:249-260

Fanimo, A.O., E. Mudama, T.O. Umukoro, and O.O. Oduguwa. 1996. Substitution of shrimp waste meal for fishmeal in broiler chicken rations. Trop. Agric. 73:201-205

Fanimo, A.O., O.O. Oduguwa, A.O. Onifade, and T.O. Olutunde. 2000. Protein quality of shrimp-waste meal. Bioresour. Technol. 72:185-188.

Fanimo, A.O., A. Susenbeth, and K.H. Sudekum. 2006. Protein utilization, lysine bioavailability and nutrient digestibility of shrimp meal in growing pigs. Anim. Feed Sci. Technol. 129:196-209.

FAO (Food and Agriculture Organization). 1989. Nutrición y alimentación de peces y camarones cultivados: manual de capacitación. http://www.fao.org/3/ contents/60051bb9-bd0e-5631-b5e1-9b5ec8e51998/ AB492S00.htm (consultado 22 oct. 2014).

Foley, S.L., A.M. Lynne, and R. Nayak. 2008. Salmonella challenges: Prevalence in swine and poultry and potential pathogenicity of such isolates. J. Anim. Sci. 86:E149-E162.

Gernat, A.G. 2001. The effect of using different levels of shrimp meal in laying hen diets. Poult. Sci. 80:633-636.

Gillet, R. 2010. Estudio mundial sobre las pesquerías de camarón. FAO. http://www.fao.org/docrep/013/ i0300s/i0300s00.htm (consultado 22 oct. 2014).

Heu, M.S., J.S. Kim, and F. Shahidi. 2003. Components and nutritional quality of shrimp processing by-products. Food. Chem. 82:235-242.

INCOPESCA (Instituto Costarricense de Pesca y Acuicultura). 2013. Información de exportación por presentación: exportaciones de productos pesqueros de Costa Rica por periodos. INCOPESCA. http:// www.incopesca.go.cr/mercado/exportacion.html (consultado 22 oct. 2014).

ISA Hendrix Genetics Company. 2009. ISA Brown: guía de manejo de la nutrición de ponedoras comerciales. ISA. http://www.isapoultry.com/ /media/Files/ISA/ Different $\% 201$ languages/Spanish/Products/CS/ISA/ Guia\%20de\%20manejo\%20de\%201a\%20nutricion $\% 20$ ISA\%20brown.pdf (consultado 22 oct. 2014).

Lahellec, C., and P. Colin. 1985. Relationship between serotypes of Salmonellae from hatcheries and rearing 
farms and those from processed poultry carcasses. Br. Poult. Sci. 26:179-186.

Mata, L. 2011. Tabla de composición de materias primas usadas en alimentos para animales. SIEDIN, San José, CRC.

Moreno, J.L. 1978. Sustitución de la harina de pescado por harina de cáscara de camarón en la alimentación de pollos de engorde. Tesis Lic., Universidad de Costa Rica, San José, CRC.

Nennich, T., and L. Chase. 2007. Dry matter determination. University of Purdue. https://www.extension.purdue. edu/dairy/articles/DMDetermination.pdf (consultado 22 oct. 2014).

Opitz, H.M., M. El-Begearmi, P. Flegg, and D. Beane. 1993. Effectiveness of five feed additives in chicks infected with Salmonella enteritidis phage type 13a. J. Appl. Poultry Res. 2:147-153.

Pan, B.S. 1990. Recovery of shrimp waste for flavorant. In: M.N. Voigt, and J.R. Botta, editors, Advances in fisheries technology for increased profitability. Technomic, SUI. p. 437-447.

Sriket, P., S. Benjakul, W. Visessanguan, and K. Kijroongrojana. 2007. Comparative studies on chemical composition and thermal properties of black tiger shrimp (Penaeus monodon) and white shrimp (Penaeus vannamei) meats. Food Chem. 103:11991207.

Torres, F. 2012. Control de acidez y oxidación en aceites y harinas de subproductos de origen animal. Engormix. http://www.engormix.com/MA-balanceados/ formulacion/articulos/control-acidez-oxidacionaceites-t4258/800-p0.htm (consultado 22 oct. 2014).

UNAM (Universidad Nacional Autónoma de México). 2014. Zootecnia y manejo de la gallina de postura. UNAM, http://avalon.cuautitlan2.unam.mx/pollos/m2_7.pdf (consultado 6 mar. 2015). 
